\section{Deformation of Cracked Net-Reinforced CONCRETE Walls}

By Zdeněk P. Bažant,' F. ASCE and Byung H. Oh'

Anstract: The deformation and crack width in concrete walls of slabs, plates. panels, and shelis reinforced by a regular rectangular net of steel bars and subjected to in-plane (membrane) internal forces is analyzed taking into accoun the frictional-dilatant behavior of rough interlocked cracks, and for the dowel action of bars at crack crossings. The tension-stiffening effect, i.e., the restrain of the bars between the cracks due to their embedment in concrete, is also taken into account. Numerical computer studies are carried out. Reinforcement designs obtained from equilibrium conditions alone on the basis of either the classical frictionless approach or the recent frictional (slip-free) approach are compared in terms of the resulting crack widths. It is found that the use of frictional equilibrium design based on a low friction coeffient (0.75) leads to a much smaller crack widith than the classical frictionless design when the reinter internal force direction. The influences of bar diameter and crack spacing on frictional dilatont behavior of cracks, the dowe action, and sis in which the are neglected leads to rather different values for the crack width.

\section{IMTRODUCTION}

This paper analyzes the in-plane deformation of walls of concrete slabs, plates, panels, or shells that are intersected by a system of parallel continuous cracks. The walls are considered reinforced by a regular net of reinforcing bars, and are subjected to given in-plane (membrane) internal forces.

The reinforcement of such walls is in practice usually designed on the basis of equilibrium conditions alone, and no conditions on the deformations are used, partly because a realistic calculation of deformations is much more difficult. When all reinforcement is laid in directions that deviate from the principal directions of given internal forces by more than about $10^{\circ}$, the usual design method leads, however, to unacceptably large cracks, as often seen in structures. Some modification of the equilibrium design method, which retains its simplicity yet gives smaller crack width in the case of a skew placement of reinforcement, therefore, is desirable.

'Prof. of Civ. Engrg. and Dir., Center for Concrete and Geomaterials, Northwestern Univ., Evanston, III. 60201.

${ }^{2}$ Visiting Research Engrg., Portland Cement Assoc., Skokie, 111

Note.-Discussion open until June 1, 1983. To extend the closing date one month, a written request must be filed with the ASCE Manager of Technical and Professional Publications. The manuscript for this paper was submitted for review and possible publication on lanuary 4, 1982. This paper is part of the Journal of Structural Engineering, Vol. 109, No. 1, January, 1983. OASCE, ISSN 07339445/83/0001-0093/\$01.00. Proc. No. 17619
The recently proposed frictional (slip-free) limit design of reinforcement is such a method. Like in the usual design, only equilibrium conditions are used. The results are identical to the classical, frictionless design when the bars are laid in the principal directions; but when they are laid skew the results are surprising. Equilibrium conditions indicate a heavier, and often much heavier, reinforcement when friction is considered than when it is not $(3,5)$. In view of this fact we may expect the frictional design for skew reinforcement to lead to a smaller deformation than the frictionless design. This is what we need; but is the reduction of deformation sufficient? Can we avoid the complexity of a design based on deformation calculations if we use the frictional equilibrium conditions?

For walls reinforced by a regular net of bars, there seem to exist at present no precise test data from which to directly answer these questions. There does exist, however, numerous test data on the deformation due to cracks. A realistic incremental model (1) as well as a secant model (4) have recently been developed to reflect the experimentally observed behavior, chiefly the dilatancy of cracked concrete due to shear which is caused by a slip displacement on the cracks. Therefore, an attempt will be made here to calculate the deformations of the cracked reinforced wall on the basis of such a model. The secant slip-dilatancy model from Ref. 4, which is somewhat less realistic but easier to use and interpret than the incremental model (1), is chosen for this purpose. To determine the overall deformation of the wall, a simple method to take into account the tension-stiffening effect due to the bond between concrete and steel, particularly the restraining effect of the solid concrete between the cracks on the overall axial extension of the steel bars, and also the effect of the dowel action of the steel bars at crack crossings, will be developed.

The present problem has already been studied analytically by $A$. Gupta (11) and by A. Pitoňák (Visiting Scholar at Northwestern University-private communication). However, they neglected, for the sake of simplicity, the frictional-dilatant behavior of cracks and the effects of tension-stiffening and dowel action. Therefore, an effort is made here to extend these valuable pioneering studies by taking into account the aforementioned effects which, as will be seen, are quite significant, as already pointed out in a preceding discussion (2).

\section{Statement of Problem}

Considered is a concrete wall reinforced by a regular net of reinforcing bars, and intersected by a system of parallel normal cracks at constant spacings. The bars, as well as the cracks, are assumed to be densely distributed. Although it would not be much more difficult to analyze skew nets or nets with bars in more than two directions, attention is limited to the rectangular nets (Fig. 1). The notations are: (1) $x, y=$ cartesian coordinate axes oriented in the directions of bars, $b_{1}, b_{2}=$ spacings of bars of $x$ and $y$ directions; $\theta=$ angle between the crack plane and axis $y$; (2) $N_{1}, N_{2}=$ given principal internal (membrane) forces in the wall, $\alpha=$ given angle between $N_{1}$ and $x ;(3) p_{x}, p_{y}=$ steel reinforcement ratios.

The reinforcement must be designed so as to assure equilibrium for 


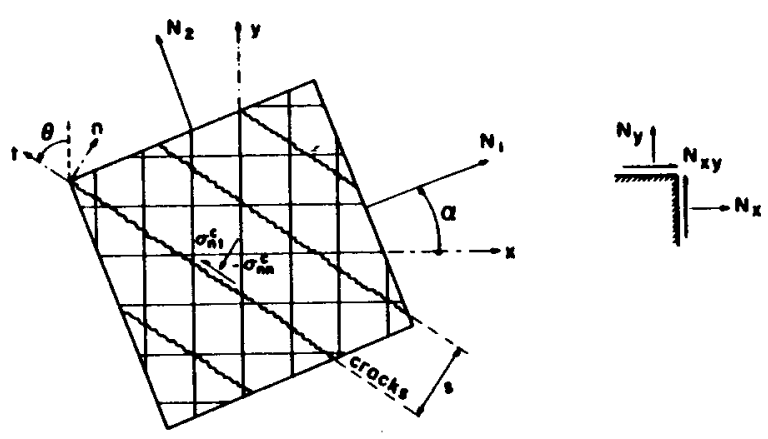

F1G. 1.-Crecked Relnforced Concrete

given $N_{1}, N_{2}$, and $\alpha$. The basic principle generally accepted for design is that a crack may exist in concrete and that it may be of any direction. By assuming that cracks exist, and neglects possible tensile resistance of concrete. This is on the side of safety. Neglecting possible friction on the cracks is, however, not on the side of safety, as has been recently discovered $(3,4,5)$. The reason simply is that a friction shear force must be accompanied by a normal compression force on the crack, causing that additional reinforcement is needed to balance the tensile reaction from this compression force. The formulas for the frictional design of reinforcement are basically given by Eqs. 6-9, and 13-15 of Ref. 3, and Eqs. 1-7 of Ref. 5. They are summarized in Appendix I with some re finements. For given friction coefficient $k$, given yield stress of steel, $f_{y}$, and given $N_{1}, N_{2}$, and $\alpha$, the calculation yields a set of $p_{x}, p_{y}$ values for which the design is safe. These values form in the $p_{x}, p_{y}$ plane a safe design envelope, on which one can easily locate the point that corresponds to the optimum design in the sense of maximum weight of steel. The results are identical to those obtained by Marti and Thürlimann (17) from the assumption of plasticity of concrete based on a yield surface with Coulomb-type friction.

\section{Tension-Stiffenino Effect}

Tension-stiffening $(8,9,10,13,16,20,21,24)$ is the excess tensile stiffness of cracked reinforced concrete as a whole, as compared to the stiffness of the reinforcing bars alone. This effect is due to transmission of tensile force by bond stresses from the steel bar into the adjacent concrete between the cracks. If this effect is disregarded, the stiffness of reinforced concrete panels, slabs, and shells is usually strongly underestimated.

Phenomenologically, the effect may be taken into account by assuming that, instead of a sudden stress drop after cracking, the tensile stress in concrete decreases gradually as the straining progresses. This approach was adopted by Scanlon (21) who used a stepped piecewise linear stress decrease, Lin and Scordelis (16), who used a smoothly curved stress decrease, and Gilbert and Warner (10), who adjusted the stress decrease law according to the proximity of reinforcement. This approach, however, mixes the tension-stiffening effect due to bond with the tensile strain-softening of concrete due to progressive microcracking, and leads to no tension stiffening when a fully (continuously) cracked concrete is considered, as is the case here.

It seems preferable then $(9,10)$ to treat the tension-stiffening as an increase of stiffness of reinforcing bars due to the restraining effect of adjacent concrete between the cracks, resulting from bond. Thus, one may seek to characterize the tension stiffening effect in terms of an equivalent cross section area of steel bar, $A_{e q}$, which is quite simple for practical computations. $A_{e q}$ may be defined as the cross section area of a bondfree "equivalent" steel bar which gives under the assumption of a uniform axial force along the bar the same overall axial extension as the actual steel bar of cross section $A_{s}$, along which the axial force fluctuates. Since the bond stresses cause the axial force at cross sections between the crack crossings to drop below its value at crack crossings, $A_{e q} \geq A_{s}$.

To obtain simple formulas, four typical, highly idealized cases may be considered:

Zero Bond Slip and Sparse Bars.-First, assume the bars to be spaced sufficiently sparsely so that they do not interact. Furthermore, although a tensioned bar always slips within a certain small distance from the crack, let this slip be neglected for a moment. For the condition of equivalence, it is best to use the strain energy. To calculate it, one must somehow approximate the strain field in concrete caused by the bond stresses. To this end, one may use the old idea of stress or strain "diffusion," assuming that the bond stress, $\tau_{b}$, "diffuses" into concrete roughly along a cone of slope $1 / \mathrm{k}$ shown in Fig. $2(b)$. This causes the normal strain in the bar direction over each cross section of the cone to

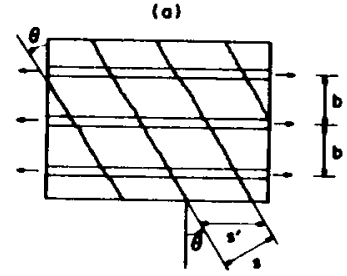

(d)
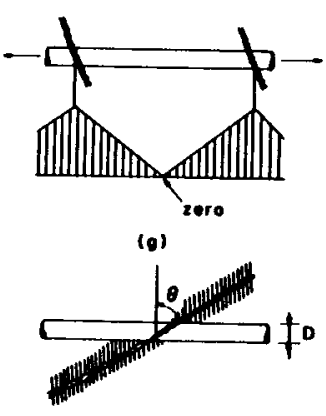
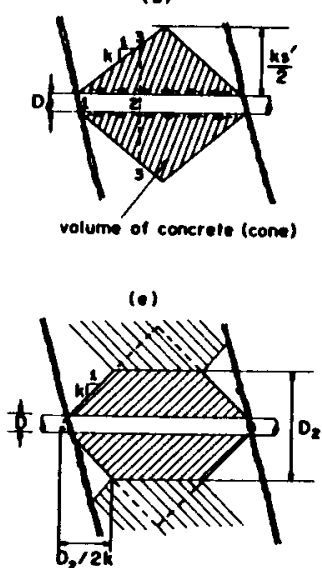

(n)

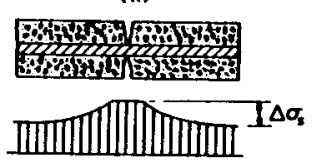

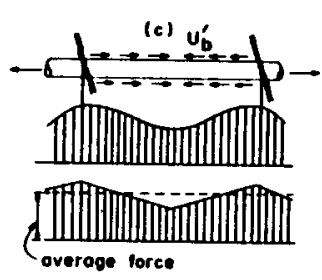

(I)
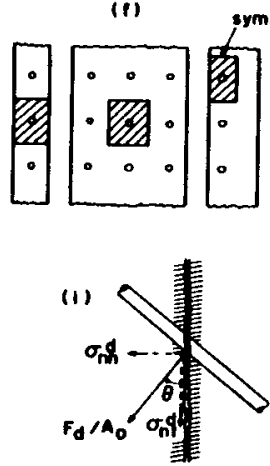

FIG. 2.-Dlagrams and Sketches for Cracked Relnforced Concrete 
be equal the axial strain, $\epsilon_{z}$, in the bar. The strain outside the cone is considered zero.

Based on this crude simplification the strain energy (per bar) of the uniaxial stresses in both the steel and concrete between two adjacent cracks is

$$
U=\frac{1}{2} E_{s} \epsilon_{s}^{2} A_{s} s^{\prime}+\frac{1}{2} E_{c} \epsilon_{g}^{2}\left[\frac{2 \pi}{3 k}\left(\frac{D+k s^{\prime}}{2}\right)^{3}-\frac{2 \pi}{3 k}\left(\frac{D}{2}\right)^{3}-\pi\left(\frac{D}{2}\right)^{2} s^{\prime}\right]
$$

in which $E_{s}, E_{c}=$ Young's moduli of steel and concrete; $A_{s}=\pi D^{2} / 4$; $D=$ diameter of the bar; and $s^{\prime}=$ spacing of the cracks along the bars $=\mathrm{s} / \cos \theta$ where $\theta=$ angle between the bars and the normal to the crack planes [Fig. 2(a)]. The slope of the diffusion cone may be taken as $k \simeq$ 0.7 , although it would be better to calibrate $k$ according to test data. The strain energy in Eq. 1 must equal the strain energy $E_{,} \epsilon_{9}^{2} A_{c q} s^{\prime} / 2$ of the equivalent steel bar, and noting that $p_{x}^{e q} / P_{x}=A_{e q} / A$, where $p=$ actual steel ratio, and $p_{e q}=$ equivalent steel ratio, this condition leads to

$\frac{p_{e q}}{p}=1+\frac{k s^{\prime}}{3 D} \frac{E_{c}}{E_{s}}\left(\frac{k s^{\prime}}{D}+3\right)$

Zero Bond Slip and Dense Bars. - If the bar spacing is too small, the cones of strained concrete considered in the first case overlap. Thus, the volume corresponding to one bar is less than that of the full cone [Fig. 2(e)]. Take the limiting cross section as a circle even though it is not; i.e., $A_{0} \approx \pi D_{2}^{2} / 4$ or $D_{2}=2 \sqrt{A_{0} / \pi}$ where $A_{0}=$ cross section area of the panel corresponding to one bar (and centrally symmetric with respect to the bar); see Fig. 2(f). Eq. 1 may now be revised as follows:

$U=\frac{1}{2} E_{s} \epsilon_{s}^{2} A_{s} s^{\prime}+\frac{1}{2} E_{c} \epsilon_{s}^{2}\left[\frac{\pi D_{2}^{2}}{4}\left(s^{\prime}-\frac{2 D_{2}-3 D}{3 k}\right)-\frac{2 \pi}{3 k}\left(\frac{D}{2}\right)^{3}-\frac{\pi D^{2}}{4} s^{\prime}\right]$

This must again equal $E_{s} \epsilon_{s}^{2} A_{e q} s^{\prime} / 2$ where $A_{e q}=A_{s} p_{e q} / p$, which yields

$\frac{p_{e q}}{p}=1+\frac{E c}{3 k s^{\prime} D^{2} E_{a}}\left[3 k s^{\prime}\left(D_{2}^{2}-D^{2}\right)-D_{2}^{2}\left(2 D_{2}-3 D\right)-D^{3}\right]$

Bond Slip Limit.-If the axial strain, $\epsilon_{z}$, of the bar is too large, the bar would slip against concrete. The bond force per unit length of the bar would then roughly equal the empirical ultimate bond force, $U_{b}^{\prime}$, as determined from pull-out tests. The axial force in the bar at the crack crossing is $\sigma_{s} A_{s}$. Due to the transfer of the load into concrete, the axial force in the bar decreases away from the crack [Fig. 2(c)]. Assuming this decrease to be linear (constant $U_{b}^{\prime}$ ), the average axial force in the steel bar is $\sigma_{s} A_{s}-U_{b}^{\prime} s^{\prime} / 4$. So the total extension of the bar between the cracks is $\left(\sigma_{s} A_{s}-U_{b}^{\prime} s^{\prime} / 4\right) s^{\prime} /\left(E_{s} A_{s}\right)$, which must equal the extension $\sigma_{s} A_{s} s^{\prime} /$ $\left(E_{s} A_{e q}\right)$ of the equivalent bar. This yields

$$
\frac{p_{e q}}{p}=\frac{1}{1-\frac{U_{b}^{\prime} s^{\prime}}{4 \sigma_{s} A_{s}}} \geq 1
$$

Limit of Zero Steel Stress. - The preceding case can lead to a negative stress in steel if the spacing of cracks is too large. Thus we must impose the limit of zero steel stress at middistance between the cracks [Fig. $2(d)$. In this case the condition of equal extensions becomes $\mathrm{\sigma}_{s} A_{s} s^{\prime} /\left(E_{s} A_{e q}\right) \geq \sigma_{s} A_{s} s^{\prime} /\left(2 E_{s} A_{s}\right)$, which yields:

$\frac{p_{\mathrm{eq}}}{p} \leq 2$

Among the four foregoing values, the minimum decides; i.e., the actual value is:

$\frac{p_{e q}}{p}=\operatorname{Min}($ Eqs. 2, 4, 5, 6)

\section{Stiffness Due to Dowel Action}

The recent formulation of Walraven (25) is adopted here. His expression for the dowel force [Fig. 2(i)] is:

$F_{d}=\frac{3 \beta^{3} E I \delta, \xi}{3+6 \beta f+6(\beta f)^{2}+2(\beta f)^{3}}$

in which $\beta=\left(\frac{G_{f} D}{4 E_{s} I_{s}}\right)^{1 / 4}, \quad E_{s} l_{s}=\frac{E_{s} \pi D^{4}}{64}$

in which $G_{f}=$ foundation modulus of concrete, $f=$ free length of bar; and $\xi=$ reduction factor due to crack opening. Tests of Elliott (6) and of Paulay, et al., (19) demonstrated that $G_{\text {, }}$ is independent of bar diameter, $D$, and led to the empirical expression

$G_{i}=34 \sqrt{f_{c}^{\prime}} \delta_{l}^{-0.85}$

in which $f_{c}^{\prime}=$ cylinder compression strength $\left(\mathrm{N} / \mathrm{mm}^{2}\right)$ and $\delta_{1}=$ tangential relative displacement on the crack (in millimeters). Furthermore, Elliot's tests (6) indicated that

$\xi=\frac{0.2}{\delta_{n}+0.2}$

in which $\delta_{n}=$ normal relative displacement on the crack (in millimeters). As for the free length, $f$, Schäfer (22) proposed, for the case of zero axial force in the bar, the free length $f_{1}=c_{r} D \tan \theta$, in which $D=$ bar diameter (in millimeters) and $c_{r}=$ empirical constant $(\approx 1.0)$. The free length here reduces as $\theta$ decreases, which reflects the fact that for nonorthogonal cracks the dowel force causes a block of concrete in the acute angle to spall off [Fig. $2(8, i)]$. The effect of the axial tensile force in the bar is to increase the free length, and according to Leonhardt's tests (15) the expression $f_{1}=c_{r} D$ tan $\theta$ may be augmented as

$f=c_{r} D \tan \theta+\frac{\Delta \sigma_{s}}{45} D$

in which $\Delta \sigma_{s}$ must be in $\mathrm{N} / \mathrm{mm}^{2}$. This represents the difference in steel 
stress between the crack crossing and a remote location.

The dowel force is normal to the bar, and when the bar is inclined with respect to the crack, the dowel force, $F_{d}$, is not parallel to the crack. The projections of $F_{d}$ per unit cross section area in the normal and tangential directions of the crack plane as denoted are $\sigma_{n n}^{d}$ and $\sigma_{n t}^{d}$, and then:

$\sigma_{n n}^{d}=\frac{F_{d}}{A_{0}} \sin \theta, \quad \sigma_{n t}^{d}=\frac{F_{d}}{A_{0}} \cos \theta$

in which $A_{0}=$ the cross section area of the wall per bar.

\section{Stiffness of Caacked Reinfonced Concrete}

To calculate the stiffness of cracked reinforced concrete, one may use a similar procedure as that in Ref. 4 , but it must now be generalized to include the dowel action and the tension stiffening.

If the contribution of the axial forces in the bars is left for later separate consideration, the normal and shear stresses that are transmitted across the crack plane by the combined action of interlock of concrete surfaces $[8,1,7,12,14,18,23,25]$ and the dowel (shear) forces in the steel bars may be expressed as $\sigma_{n n}^{c}=\sigma_{n n}^{c r}+\sigma_{n n}^{d}, \sigma_{n t}^{c}=\sigma_{n t}^{c r}+\sigma_{n t}^{d}$ where $\sigma_{n n}^{c r}$ and $\sigma_{n t}^{c r}$ are the normal and shear stresses transmitted through the crack plane by the action of concrete. (Without concrete, the bars can transmit their axial forces but not the dowel forces.) The frictional shear stresses, $\sigma_{n !}^{*}$, and the associated normal displacements are assumed to be governed (4) by the following friction law and the dilatancy law:

for $\quad \sigma_{n n}^{c r} \leq 0: \quad\left|\sigma_{m l}^{\pi}\right|=-k \sigma_{n n}^{\pi}+c \quad$ (frictional slip);

for $\delta_{n} \geq 0: \quad \delta_{n}=\alpha_{d}\left|\delta_{1}\right|+e$ (dilatancy)

in which $k=$ friction coefficient; $c=$ cohesion; $\alpha_{d}=$ dilatancy ratio; and $e=$ initial dilatancy.

From the macroscopic point of view, the effect of the relative displacements, $\delta_{n}$ and $\delta_{1}$, on many densely distributed parallel cracks of mean spacing, $s$, is to produce the averaged strains

$\epsilon_{n t}^{\sigma}=\frac{\delta_{n}}{s} ; \quad \epsilon_{t 1}^{\sigma r}=0 ; \quad \gamma_{n t}^{\sigma r}=\frac{\delta_{t}}{s}$

in which $\gamma_{n t}^{c}=$ shear angle $=2 \epsilon_{n t}^{\sigma}$. The total strains of concrete containing many densely distributed parallel cracks may then be expressed as

$\epsilon=\epsilon^{c}+\epsilon^{c r}$

in which $\epsilon^{c r}=$ column matrix $\left(\epsilon_{n n}^{c r}, \epsilon_{11}^{c r}, \gamma_{n t}^{c r}\right)^{T} ; T$ denotes a transpose; and $\epsilon$ and $\epsilon^{c}$ are similar matrices representing the total strains and the strains in the concrete between the cracks. Assuming the concrete between the cracks to be isotropic and elastic, one may then write

$\epsilon^{c}=C_{c} \sigma^{c} ; \quad C_{c}=\left[\begin{array}{ccc}E_{c}^{-1} & -v E_{c}^{-1} & 0 \\ & E_{c}^{-1} & 0 \\ s y m . & & G_{c}^{-1}\end{array}\right]$ in which $\sigma^{c}=\left(\sigma_{n n}^{c}, \sigma_{u}^{c}, \sigma_{n t}^{c}\right)^{T} ; C_{c}=$ the compliance matrix of uncracked concrete; and $E_{c}, \nu$, and $G_{c}$ are its Young's modulus, Poisson's ratio, and shear modulus, respectively. When the concrete is in a state of plane strain rather than plane stress, $E_{c}$ and $v$ must be replaced by $E_{c}$ $\left(1-v^{2}\right)$ and $v /(1-v)$, respectively. Note that $E_{c}$ and $G_{c}$ should be taken here as the secant moduli.

Substituting from Eqs. 16 and $17 \delta_{n}=s\left(\epsilon_{n n}-\epsilon_{n n}^{c}\right)$ and $\delta_{t}=s\left(\gamma_{n t}-\right.$ $\left.\gamma_{n 1}^{c}\right)$ into Eq. 15, and expressing $\epsilon_{n n}^{c}$ and $\gamma_{n t}^{c}$ from Eq. 18, one obtains

$\epsilon_{n n}-\frac{\sigma_{n n}^{c}-\nu \sigma_{t t}^{c}}{E_{c}}= \pm \alpha_{d}\left(\gamma_{n t}-\frac{\sigma_{n t}^{c}}{G_{c}}\right)+\frac{e}{s}$

Noting that $\epsilon_{u}^{c}=\epsilon_{\|}$and substituting $\sigma_{u}^{c}=E_{c} \epsilon_{\|}+\nu \sigma_{n n}^{c}=E_{c} \epsilon_{u}+\nu\left(\sigma_{n n}^{c r}\right.$ $+\sigma_{n n}^{d}$ ) and $\sigma_{n t}^{c}=\mp k \sigma_{n n}^{c} \pm C+\sigma_{n t}^{d}$ into Eq. 19, one further obtains

$$
\begin{aligned}
& {\left[\frac{1-v^{2}}{E_{c}}+\frac{1}{G_{c}}\left( \pm \alpha_{d}\right)( \pm k)\right] \sigma_{n n}^{c r}=\epsilon_{n n}+v \epsilon_{t t} \mp \alpha_{d} \gamma_{n t}+\frac{1}{G_{c}}\left( \pm \alpha_{d}\right)( \pm c)} \\
& -\frac{e}{s}-\left(\frac{1-v^{2}}{E_{c .}}\right) \sigma_{n n}^{d}+\frac{1}{G_{c}}\left( \pm \alpha_{d}\right) \sigma_{n t}^{d} \ldots \ldots \ldots \ldots \ldots \ldots \ldots \ldots \ldots \ldots \ldots \ldots \ldots \ldots \ldots \ldots \ldots \ldots
\end{aligned}
$$

in which \pm and $\mp$ signs distinguish between slip to the right (top signs) and to the left (bottom signs). Expressing $\sigma_{n n}^{c r}$ from Eq. 20 and substituting this into Eq. 14, one obtains $\sigma_{n n}^{c r}$ and $\sigma_{n t}^{c r}$. To get the total stresses of concrete alone, one must now make use of the equilibrium relations $\sigma_{n n}^{c}=\sigma_{n n}^{c r}+\sigma_{n n}^{d}$ and $\sigma_{n t}^{c}=\sigma_{n t}^{c r}+\sigma_{n t}^{d}$. Noting that $\sigma_{n}^{c}=E_{c} \epsilon_{t t}+\nu \sigma_{n n}^{c}=$ $E_{c} \epsilon_{n}+\nu\left(\sigma_{n n}^{\pi}+\sigma_{n n}^{d}\right)$, it follows that

$\boldsymbol{\sigma}^{c}=D^{c} \epsilon+\mathbf{f}$

in which $D^{c}=E^{*}\left[\begin{array}{ccc}1 & v & \mp \alpha_{d} \\ \nu & \frac{E_{c}}{E^{*}}+\nu^{2} & \mp \alpha_{d} \nu \\ \mp k & \mp k v & \left( \pm \alpha_{d}\right)( \pm k)\end{array}\right]$

$f=\left\{\begin{array}{c}g_{1} E^{*}+\sigma_{n n}^{d} \\ \nu g_{1} E^{*}+\nu \sigma_{n n}^{d} \\ \mp k g_{1} E^{*} \pm c+\sigma_{n t}^{d}\end{array}\right\}$

$\left(E^{*}\right)^{-1}=\frac{1-\nu^{2}}{E_{c}}+\frac{1}{G_{c}}\left( \pm \alpha_{d}\right)( \pm k)$

$g_{1}=\frac{1}{G_{c}}\left( \pm \alpha_{d}\right)( \pm c)-\frac{e}{s}-\left(\frac{1-v^{2}}{E_{c}}\right) \sigma_{m n}^{d}+\frac{1}{G_{c}}\left( \pm \alpha_{d}\right) \sigma_{n t}^{d}$

Matrix $D^{c}$ represents the stiffness matrix of concrete that contains closely spaced parallel cracks whose surfaces slip and are in contact. The stiffness of reinforcement may now be brought into the picture. The total stress, $\sigma=\left(\sigma_{n n}, \sigma_{u}, \sigma_{n t}\right)^{T}$, in the crack coordinates $(n$ and $t)$ may then be calculated as: 


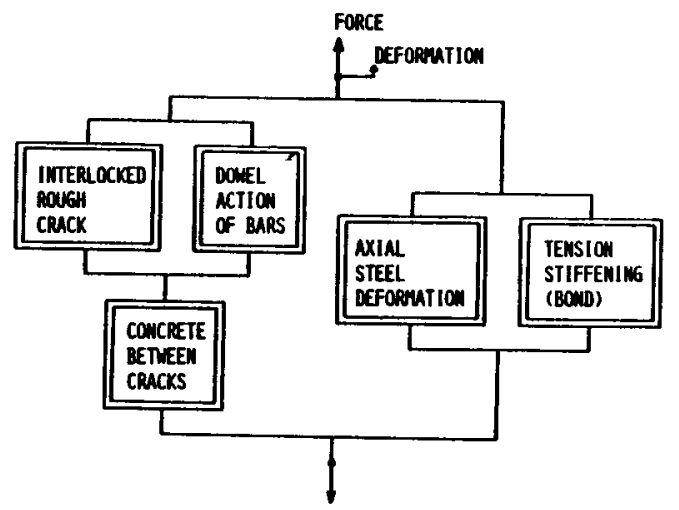

FIG. 3.-Scheme of Superimposing Various Stiffnesses and Compllances

Here $D$ represents the sum of the stiffness, $D^{c}$, due to concrete and all stiffness matrices $\mathbf{D}_{i}^{s}$ for the axial deformation of the bar systems $i=1$ 2, ...N (excluding the dowel action), after these matrices are transformed with the help of rotation matrices, $\mathbf{R}_{i}$, from the bar coordinates to the crack coordinates. Thus:

$\mathbf{D}=\mathbf{D}^{c}+\sum_{i=1}^{n} \mathbf{R}_{i}^{T} \mathbf{D}_{i}^{s} \mathbf{R}$

in which $\mathbf{D}_{i}^{s}=\left[\begin{array}{ccc}p_{i}^{e q} E_{s} & 0 & 0 \\ 0 & 0 & 0 \\ 0 & 0 & 0\end{array}\right] ; \quad \mathbf{R}_{i}=\left[\begin{array}{ccc}C^{2} & S^{2} & C S \\ S^{2} & C^{2} & -C S \\ -2 C S & 2 C S & C^{2}-S^{2}\end{array}\right]$

Here $C=\cos \theta_{i} ; S=\sin \theta_{i} ; E_{s}=$ Young's modulus of steel; and $p_{i}^{\text {eq }}=$ equivalent steel ratio for the $i$ th bar system $=A_{e, 4} / A_{0}$ for the $i$ th $b a r$ system. The tension stiffening effect is thus taken into account under
$p_{i}^{\text {eq. }}$.

Note the separate and different treatment of the axial and shear (dowel) response of the steel bars. The axial stiffness, after being corrected for tension stiffening due to bond, is superimposed on the stiffness of cracked concrete as a whole. The shear (dowel) stiffness of bars meanwhile is superimposed on the stiffness of the crack alone (Fig. 3). The reason consists in the fact that the overall axial deformations of steel bars and of cracked concrete must be the same, and that the mean shear stress in solid concrete on the plane located midway between the cracks should equilibrate the shear stresses on the crack due to friction and to
dowel action.

\section{Numerical Studies and Amalysis of Results}

For the purpose of numerical calculations, the value $N_{1}^{D}$ of the principal internal force due to the design loads is given. Let $0.75 N^{D}$ be due to the dead load, and $0.25 N_{1}^{D}$ to the live load. According to the ACI Code, the ultimate design must then be based on $N_{1}=1.4\left(0.75 N_{1}^{D}\right)$ $+1.7\left(0.25 N_{1}^{D}\right)=1.475 N_{1}^{D}$. The ratio $m=N_{2} / N_{1}$ and the angle, $\alpha$, are also specified. The properties considered in numerical examples are $E_{c}$ $=24,800 \mathrm{MN} / \mathrm{m}^{2} ; E_{s}=200,000 \mathrm{MN} / \mathrm{m}^{2} ; \nu=0.18 ; f_{c}^{\prime}=27.6 \mathrm{MN} / \mathrm{m}^{2} ; f_{y}$ $=276 \mathrm{MN} / \mathrm{m}^{2}$; bar spacing $b=15 \mathrm{~cm} ; N_{1}^{D}=400 \mathrm{kN} / \mathrm{m}$; plate thickness $h=10 \mathrm{~cm}$; bar diameter $D=1.27 \mathrm{~cm}$ (except where indicated differently); and capacity reduction factor $\phi=0.9$. For ultimate bond force the formula $U_{b}^{\prime}=35 \sqrt{f_{c}^{\prime}}$, with ( $f_{c}^{\prime}$ in psi, (26) is used. The crack spacing $s$ is considered as $5 \mathrm{~cm}$ except where indicated differently. (In reality, of course, the crack spacing is also an unknown, depending on the steel ratio, bar diameter, type of concrete, and ultimate bond stress.)

A computer program has been written to calculate a great number of cases. For each case, the values of $N_{1}, m\left(=N_{2} / N_{1}\right)$, and $\alpha$ are assigned. On their basis the optimum reinforcement ratios $p_{x}$ and $p_{y}$ are determined using the formulas given in Refs. 3 and 5 (Appendix I). This is done for several values of the crack friction coefficient: $k=0.75, k=1.7$ (the most realistic value), and $k \rightarrow \infty$. The last value of $k$ gives results which are equivalent to the classical frictionless design of reinforcement $(3,5)$.

After determining $p_{x}$ and $p_{y}$, the program calculates average membrane strains $\left(\epsilon_{x}, \epsilon_{y}, p_{x y}\right)$ of the reinforced wall, and the relative tangential and normal displacements on the cracks $\delta_{\text {, }}$ and $\delta_{n}\left(\delta_{n}\right.$ is called the crack width even though the asperities may be in contact at nonzero $\delta_{n}$ ). The slip-dilatancy model, described in Ref. 4 and extended here, is used for this purpose.

The maximum crack width, $\boldsymbol{\delta}_{d, \text { max }}$, is found in the program by scanning the entire range of crack angle $\theta$ for a given value of $\alpha$. For each $\alpha$ a series of discrete values of $\theta$, increasing from $0^{\circ}-180^{\circ}$, by steps of $1^{\circ}$, is selected. The crack width is then solved for each of them, and the case giving the maximum value is located among the results. For simplicity, the coefficients characterizing the cracks are assumed to be constant: also $c=e=0$. For $k$ and $\alpha_{d}$ it seems appropriate to select the values that correspond to the load at which the cracks begin to slip and open significantly. According to tests, $k$ is roughly 1.7 when the crack surfaces undergo a large slip (18). Moreover, the examination of the calculated response curves based on a theory that was calibrated by several test series (1) indicates also that $k \simeq 1.7$ and $\alpha_{d} \simeq 1.0$. Therefore, $k=$ 1.7 and $\alpha_{d}=1.0$ are selected as typical and most realistic values for the slip-dilatancy model.

The results of numerical studies are plotted in Figs. 4-7. Fig. 4 shows that consideration of tension-stiffening causes a significant reduction (from $12 \%-16 \%$ ) in the resulting crack width, and that the additional consideration of dowel action causes a further appreciable reduction (about 9\%). With regard to the effect of the angular deviation of reinforcement from the principal force direction, Fig. 5 shows the results when the tension-stiffening and the dowel action are both neglected (dashed lines) and when they are both taken into account. All this is shown for reinforcement designs obtained from equilibrium conditions alone on the basis of friction coefficients $k=0.75,1.7$, and $\infty$. It is seen from the calculated plots that the use of $k=0.75$ in the design, as compared to the frictionless design $(k=\infty)$, greatly offsets the increase of crack width due to angular deviation of reinforcement over the crack 

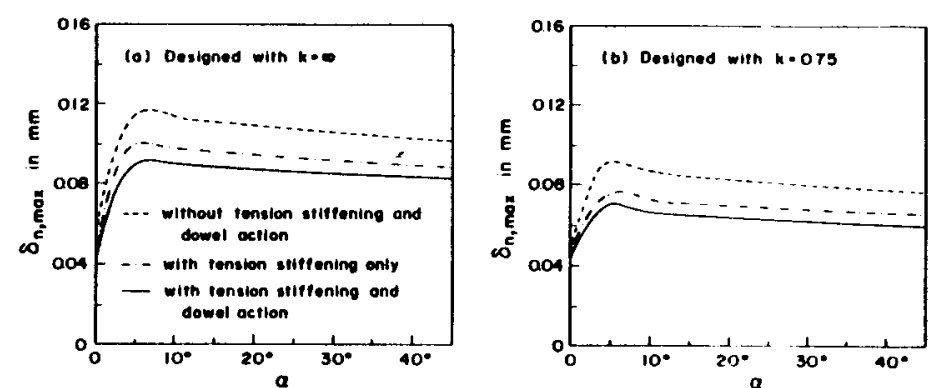

FIG. 4.-Effect of Tension Stiffening and Dowel Action on Crack Width ( $m=0$, $s=\mathbf{5 0} \mathbf{~ m m )}$
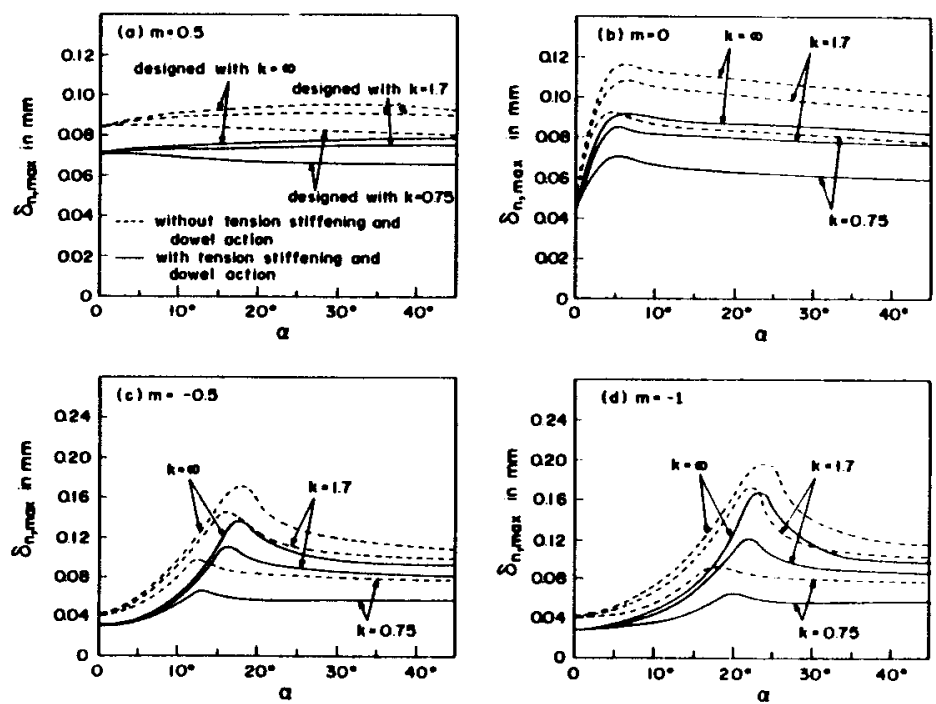

FIG. 5.-Comparison of Maximum Crack Width Between Frlctional (Slip-Free) and Frictionless Designs with and without Tension Stiffening and Dowel Action ( $s=$ $50 \mathrm{~mm}, D=12.7 \mathrm{~mm}$ )

width for parallel reinforcement lin Fig. $5(d)$, it reduces a five-fold increase to a two-fold increase]

Fig. 6 shows again the effect of the angular deviation of reinforcement, now for the designs based only on $k=1.7$ and, for different crack spacings and different bar diameters, the magnitude of which affects both the tension stiffening and the dowel action. It is seen that for a large crack spacing ( $100 \mathrm{~mm}$ or 4 in.) the influence of the bar diameter upon the crack width increase due to the angular deviation of reinforcement is much more intense than it is for a small crack spacing $(25 \mathrm{~mm}$ or 1 in.).

Finally Fig. 7 shows the results obtained with the consideration of tension-stiffening and dowel action for different crack spacings and for dif-
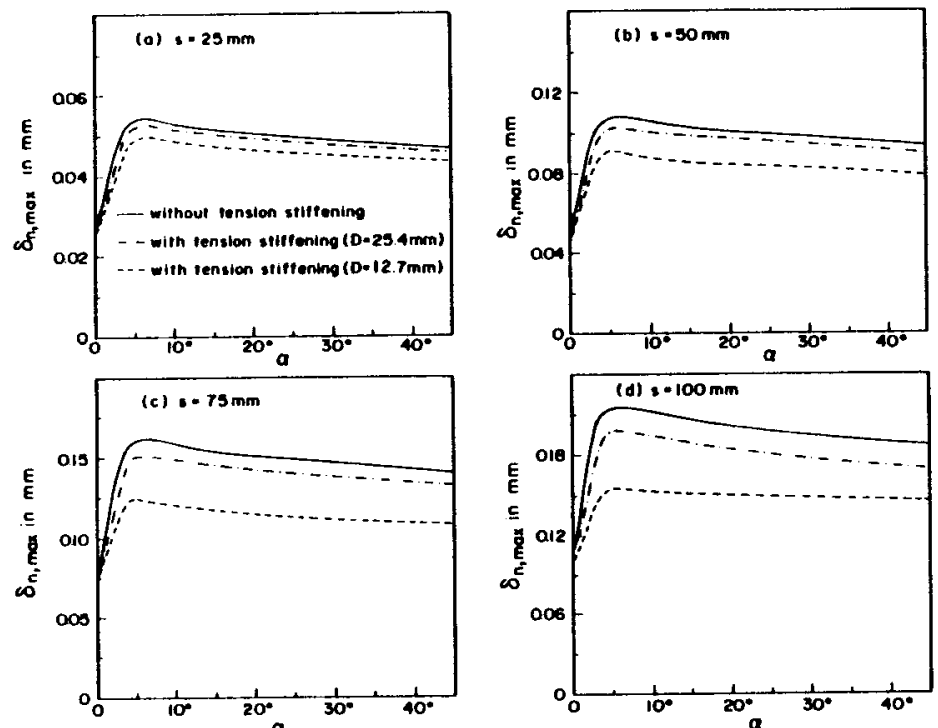

FIG. 6.-Effect of Bar Diameter and Crack Spacing on Tension Stiffening ( $m=0$, Bar Designed with $k=1.7$ )
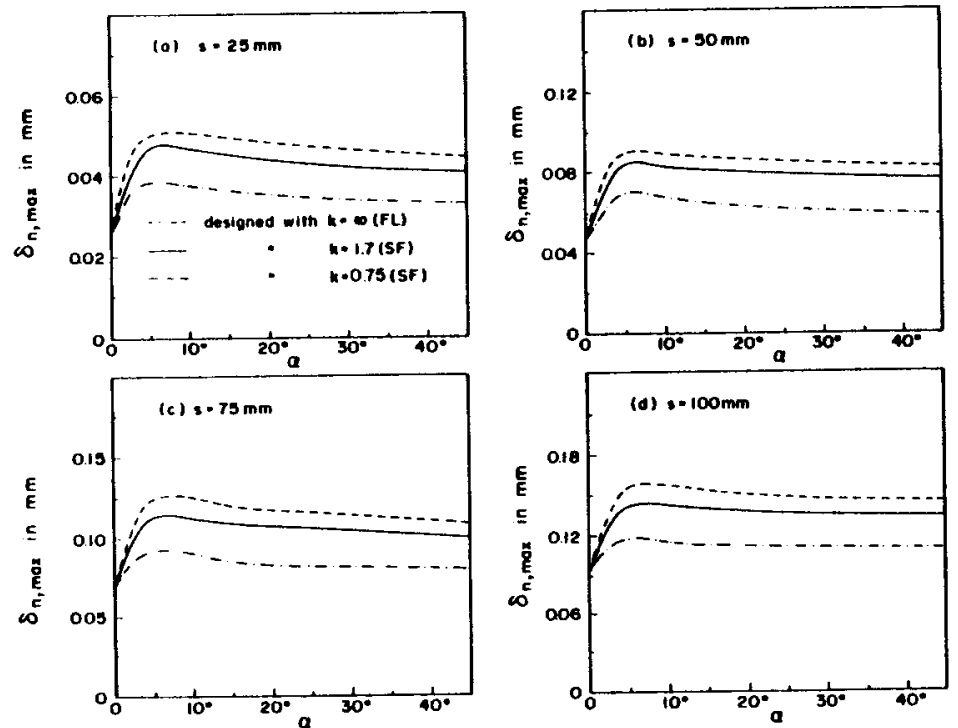

FIG. 7.-Comparison of Crack Widths for Varlous Dealgns with Tension Stiffening and Dowel Action and Varlous Crack Spacing $(m=0, D=12.7 \mathrm{~mm})$ 
ferent reinforcement designs based on different friction coefficients $(k$ $=0.75,1.7$, and $\infty)$. The crack width increase due to the angular deviation of reinforcement is somewhat less for larger crack spacings $(80 \%$ vs. $50 \%$ increase for $k=1.7$ ) but is generally not strongly dependent on the assumed crack spacing (if the bar diameter is small; $D=12.7 \mathrm{~mm}$ or 0.5 in.).

Even though experimentally verified material properties have been used, one must keep in mind that the foregoing results represent essentially simplified theoretical deductions. It would be useful to carry out measurements on reinforced panels and compare them with the present results.

\section{Summary and Conclusions}

The deformation and crack width of concrete walls reinforced by a regular rectangular net of reinforcing bars and subjected to in-plane (membrane) internal forces is analyzed on the basis of realistic models for the frictional dilatant behavior of rough interlocked cracks, and for the dowel action of bars at crack crossings. The tension stiffening effect, i.e., the restraining effect of the solid concrete between the cracks caused by bond stresses, is taken into account in terms of an equivalent steel ratio and is calculated by considering either slipping or nonslipping bars. The dowel action is modeled as an additional stiffness in the stress-displacement relation for the cracks. Extensive numerical computer studies have been conducted, and reinforcement designs obtained on the basis of equilibrium conditions alone of either the classical frictionless approach or the recent frictional (slip-free) approach are compared in terms of the resulting crack widths for these different designs. The secant slipdilatancy model is used.

The computer results lead to the following conclusions.

1. The tension stiffening effect reduces the calculated crack width by $10 \%-25 \%$, and the dowel action further by as much as $10 \%$. So, it is quite important to consider these effects in calculations.

2. The reinforcement designs obtained with different crack friction coefficients often lead to rather different crack widths for the same loads. The difference is significant (up to about $160 \%$ ) when the bar direction deviates from the principal tensile force by more than about $5 \%$, while for reinforcement that is laid in the direction of the principal tensile force no difference is obtained.

3. The use of friction coefficient $k=0.75$ (which is lower than the realistic value of 1.7 ) in the equilibrium design of reinforcement assures that the crack width for any direction of reinforcement is no more than twice the crack width for parallel reinforcement. By contrast, for the frictionless design, for which $k \rightarrow \infty$, the crack width for skew reinforcement may be as much as five-times larger than for parallel reinforcement. Thus, the simple use of the frictional design allows a significant reduction of the crack width for the cases of arbitrary skew reinforcement without the need of actually calculating the deformations and checking them against some limit. This is a much more difficult task if it should be carried out realistically (taking into account the aggregate interlock, dowel action, and tension stiffening).

The influence of bar diameter on the crack width increase due to 4. The influence of back spacing stronger angular deviation of reck spacing. For small diameters ( $\leq 0.5 \mathrm{in}$.; $13 \mathrm{~mm}$ ), than it is for small crack spacing. the influence of crack spacing is negligible, while for large diameters (1 in.; $25.4 \mathrm{~mm}$ ) it is not.

5. The classical approach, in which the frictional dilatant behavior of 5. The classicaled in the deformation analysis and the cracks are ascracks is neglected in the deformation analysis and the cracks are assumed to be oriented so that no slip displacement occurs on them (i.e. to be normal to the maximum principal strain direction), yields different values of the crack width.

\section{ACKNOWLEDGMENT}

Financial support under National Science Foundation Grant No. Financial support under National Scitern is gratefully acknowledged. CME8009050 to Northwestern University is gratefully acknowledged. Andrej Pitonák, Visiting Scholar at Northwestern Universich on leave from USU.S.-Czechoslovakia Scientific Exchange Pratislava, is thanked for carrying TARCH, Slovak Academy of Sciences, Bratislava, is thanked calculations which provided the stimulus for this work.

\section{Appendix 1.-Design of Optimum Reinforcement}

A summary of the design procedure according to Refs. 3 and 5 will now be given. It will be also indicated how it should be adjusted to take into account the minimum reinforcement requirements. Let $n_{x}=$ $N^{s} / N_{1}$ and $n_{y}=N_{y}^{s} / N_{1}$ in which $N_{1}, N_{2}=$ principal internal forces $\left(N_{1}\right.$ $N_{x}^{s} / N_{1}$ and $n_{y}=N_{y}^{s} / N_{1}$ in which $N_{1}, N_{2}=$ principal interces. The safe design
$\geq N_{2}, N_{1}>0$ ), and $N_{x}^{s}, N_{y}^{s}=$ reinforcement yield forces. envelope is given by

$\left[\left(n_{x}-n_{x}^{0}\right)-\beta_{1}\left(n_{y}-n_{y}^{0}\right)\right]\left[\left(n_{y}-n_{y}^{0}\right)-\beta_{1}\left(n_{x}-n_{x}^{0}\right)\right]=\left(2 \beta_{2} n_{x y}^{0}\right)^{2} \ldots \ldots$ (28) in which $\left(n_{x}^{0}, n_{y}^{0}\right)=[1+m \pm(1-m) \cos 2 \alpha] / 2 ; n_{x y}^{0}=(1-m)(\sin 2 \alpha) /$ 2; $\beta_{2}=1 /(1+\sin \beta)$; and $\beta_{1}=(1-\sin \beta) \beta_{2}$. The optimum values are: $\left(n_{x}\right)_{a p t}=1+\frac{1}{2}(1-m) \sin 2 \alpha(\operatorname{cosec} \beta-\tan \alpha) \ldots \ldots \ldots \ldots \ldots \ldots$

$\left(n_{y}\right)_{\text {opt }}=m+\frac{1}{2}(1-m) \sin 2 \alpha(\operatorname{cosec} \beta+\tan \alpha)$

in which $\boldsymbol{m}=N_{2} / N_{1}, \boldsymbol{\alpha}$ is shown in Fig. $1 ; \beta=\arctan (k) ;$ and $k=$ friction in $w$ hich $m$, the optimum reinforcement ratios coefficient. Now, from Eqs. 29 and 30 , the optimum rech $\sigma_{1,}=N_{1,4} / \mathrm{h}$

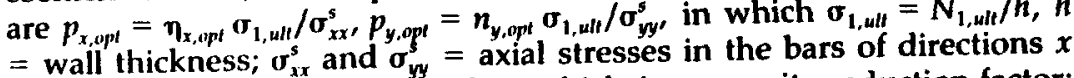
and $y\left(\sigma_{x x}^{s}\right.$ and $\sigma_{y y}^{s}$ is taken as $\phi f_{y}$ in which $\phi=$ capacity reduction factor; and $y\left(\sigma_{x x}^{s}\right.$ and $\sigma_{y y}^{s}$ is take $f_{4}=$ yield stress of bar). Assuming the dead-to-live load ratio $3: 1$, and introducing the respective load factors 1.4 and 1.7, leaves $N_{1.4 l t}=$ $1.4 N_{1 D}+1.7 N_{11}=1.475 N_{1}^{D}$. As already mentioned, one must use in Eqs. 1.4N $N_{10}$ thesign value $N_{1}=1.475 N_{1}^{D}$ where $N_{1}^{D}$ is the design value of $N_{1}$. Note that the safe design requires $n_{x} \leq r_{x}=f_{y} p_{x} / \sigma_{1}$ and $n_{y}$ $\leq r_{y}=f_{y} p_{y} / \sigma_{1}$. 
Some cases give a negative value for $n_{x, \ldots y, t}$ or $n_{y, 0, t)}$. This means that no tensile reinforcement is needed in the corresponding direction in this case. One must, however, use at least the minimum shrinkage and temperature reinforcement specified by section 7.12 of ACl Code $(0.002$ in case of a slab). The complete design procedure when either Eq. 29 or Eq. 30 gives a negative value is then as follows:

Case 1.-If $n_{x} \leq 0$, set $p_{x}=p_{x, \min }$ (given, e.g., 0.002), and $n_{x}=n_{x, \min }$ $=p_{x, \text { in }} \sigma_{x x}^{s} / \sigma_{1, \text { ult }}$. Then, if $n_{x, \min }<r_{x p}$, solve Eq. 28 for $n_{y}=\left(n_{y}\right)_{\text {opt }}$. If $n_{x, \text { min }}$ $\geq r_{x p}$, substitute $n_{y}=\left(n_{y}\right)_{o p t}=r_{y p}$; in which [see Fig. 1(b) of Ref. 5]

$\left.\left.r_{x P}=1+n_{x y}^{0}[\operatorname{cosec} \beta+\sin \beta) \sec \beta-\tan \alpha\right)\right]$

$\left.r_{y p}=m+n_{x y}^{0}[(\operatorname{cosec} \beta-\sin \beta) \sec \beta+\tan \alpha)\right] \ldots \ldots \ldots \ldots \ldots \ldots$

Case 2.-If $n_{y} \leq 0$; set $p_{y}=p_{y, \min }$ (given), and $n_{y}=n_{y, \min }=p_{y, \min } \sigma_{y y}^{\mathrm{s}} /$ $\sigma_{1, \text { ult }}$. Then if $n_{y, \text { min }}<r_{y Q}$, solve Eq. 28 for $n_{x}=\left(n_{x}\right)_{1, y,}$; and if $n_{y, \text { min }} \geq r_{y(1)}$ substitute $n_{x}=\left(n_{x}\right)_{\text {opt }}=r_{x Q}$ in which [Fig. 1(b) of Ref. 5]

$r_{x Q}=1+n_{x y}^{0}[(\operatorname{cosec} \beta-\sin \beta) \sec \beta-\tan \alpha]$

$r_{y Q}=m+n_{x y}^{0}[(\operatorname{cosec} \beta+\sin \beta) \sec \beta+\tan \alpha]$

\section{Appendix U.-References}

1. Bažant, Z. P., and Gambarova, P., "Rough Cracks in Reinforced Concrete," Journal of the Structural Division, ASCE, Vol. 106, No. ST4, Proc. Paper 15330, Apr., 1980, pp. 819-842.

2. Bažant, Z. P., and Oh, B. H., discussion of "Membrane Reinforcement in Shells," by A. K. Gupta, Journal of the Structural Division, ASCE, Vol. 108, No. ST2, Proc. Paper 16834, Feb., 1982, pp. 490-493.

3. Bažant, Z. P., and Tsubaki, T., "Concrele Reinforcing Net: Optimum SlipFree Limit Design," Journal of the Structural Division, ASCE, Vol. 105, No. ST2, Proc. Paper 14344, Feb., 1979, pp. 327-346.

4. Bažant, Z. P., and Tsubaki, T., "Slip-Dilatancy Model for Cracked Reinforced Concrete," Journal of the Siructural Division, ASCE, Vol. 106, No. ST9, Proc. Paper 15704, Sept., 1980, pp. 1947-1966.

5. Bažant, Z. P., Tsubaki, T., and Belytschko, T. B., "Concrele Reinforcing Net: Safe Design," Journal of the Structural Division, ASCE, Vol. 106, No. ST9, Proc. Paper 15705, Sept., 1980, pp. 1899-1906.

6. Elliot, A. F., "An Experimental Investigation of Shear Transfer across Cracks in Reinforced Concrete," thesis presented to Cornell University, at Ithaca, N.Y., in June, 1974, in partial fulfillment of the requirements for the degree N.Y., in June, 1974,
of Master of Science.

7. Fenwick, R. C., and Paulay, T., "Mechanisms of Shear Resistance of Concrete Beams," Journal of the Structural Dirision, ASCE, Vol. 94, No. ST10, Proc. Paper 2325, Oct., 1968, pp. 2325-2350.

8. "Finite Element Analysis of Reinforced Concrete Structures," by the ASCE Structural Division Committee on Finite Element Analysis of Reinforced Concrete Structures, A. H. Nilson, Chmn., ASCE, Special Publication, N.Y., 1981 (Chapters 3, 4, 5)

9. Floegl, H., and Mang, H., "On Tension Stiffening in Cracked Reinforced Concrete Slabs and Shells Considering Geometric and Physical Nonlinearity," Report, Institut für Baustatik und Festigkeitslehre, Technische Universität Wien, Wien, Austria, 1980.

10. Gilbert, R. I., and Warner, R. F., "Tension Stiffening in Reinforced Concrete Slabs," Journal of the Structural Division, ASCE, Vol. 104, No. ST12, Proc. Paper 14211, Dec., 1978, pp. 1885-1900.
11. Gupta A K "Membrane Reinforcement in Shells," Journal of the Structural Division ASCE Vol. 107, No. ST1, Proc. Paper 15975, Jan., 1981, pp. 41-56.

12. Houde, J., and Mirza, M. S., "A Finite Element Analysis of Shear Strength of Reinforced Concrete Beams," Shear in Reinforced Concrete, Vol. 1, Special Publication SP-42, American Concrete Institute, Detroit, Mich., 1974.

13. Kabir, A. F., "Nonlinear Analysis of Reinforced Concrete Panels, Slabs, and Shells for Time Dependent Effects," UC-SESM Report No. 76-6, University of California at Berkeley, Berkeley, Calif., Dec., 1976.

14. Laible, J. P., White, R. H., and Gergely, P., "An Experimental Investigation of Seismic Shear Transfer Across Cracks in Concrete Nuclear Containment of Seismic Shear Transfer Across Cracks in Concrete Nuclear Contal Publi-

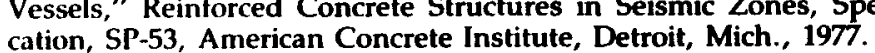

15. Leonhardt, F., "Vorlesungen über Massivbau," Vierten Teil, Nachweis der Gebrauchsfähigkeit, Springer Verlag, Berlin, Heidelberg, New York.

16. Lin, C. S., and Scordelis, A. C., "Nonlinear Analysis of RC Shells of Genera Form," Iournal of the Structural Division, ASCE, Vol. 101, No. ST3, Proc. Paper 11104, Mar., 1975, pp. 523-538.

17. Marti, P., and Thürlimann, B. "Fliessbedingung für Stahlbeton mit Berücksichtigung der Betonzugfestigkeit," Beton-und Stahlbetonbau, Vol. 72, No. 1, Jan., 1977, pp. 7-12.

18. Paulay, T., and Loeber, P. J., "Shear Transfer by Aggregate Interlock," Shear in Reinforced Concrete, Special Publication, SP-42, American Concrete Institute, Detroit, Mich., 1974, pp. 1-15.

19. Paulay, T., Park, R., and Phillips, M. H., "Horizontal Construction Joints in Cast-in-Place Reinforced Concrete," Shear in Reinforced Concrete, Special Publication SP-42, American Concrete Institute, Detroit, Mich., 1974, Pp. 599-616.

20. Salem, M H and Mohraz B "Nonlinear Analysis of Planar Reinforced Concrete Structures," Civil Engineering Studies, SRS No. 410, University of Illinois at Urbana-Champaign, Urbana, III., July, 1974.

1. Scanlon, A., "Time Dependent Deflections of Reinforced Concrete Slabs," thesis presented to the University of Alberta, at Edmonton, Alberta, Canada, in 1971, in partial fulfillment of the requirements for the degree of Doctor of Philosophy.

2. Schäfer, H., "Zur Berechnung von Stahlbetonplatten," Dissertation, TU Darmstadt, 1976.

23. Taylor H. P. "The Fundamental Behavior of Reinforced Concrete Beams in Bending and Shear" Shear in Reinforced Concrete, Vol. 1 Special Publication SP-42, American Concrete Institute, Detroit, Mich., 1974.

24. VanGreunen, J., "Nonlinear Geometric, Material and Time Dependent Analysis of Reinforced and Prestressed Concrete Slabs and Panels," UC-SESM Report No. 79-3, University of California at Berkeley, Berkeley, Calif., Oct., 1979.

25. Walraven, I. C "Aggregate Interlock: A Theoretical and Experimental Analysis," Report, Delft University Press, Delft, Netherlands, 1980.

26. Winter, G., and Nilson, A. H., "Design of Concrete Structures," McGrawHill Book Co., Inc., New York, N.Y., 1972. 